\title{
BAGAIMANA KEPRIBADIAN DAN PEMBERDAYAAN PSIKOLOGIS MENINGKATKAN PERILAKU PROAKTIF KARYAWAN START-UP?
}

\author{
Mokhamad Arif Saifullah, Medianta Tarigan, dan Gemala Nurendah \\ Dapartemen Psikologi, Universitas Pendidikan Indonesia \\ E-mail: arif.mokhamad@student.upi.edu; medianta.tarigan@gmail.com;
}

\author{
gemalanurendah@yahoo.com
}

\begin{abstract}
This research aimed to know the effect of personality traits and psychological empowerment on proactive behavior of start-up company employees. The research used quantitative method with 350 participants. The instruments were Big Five Inventory (BFI), Psychological Empowerment Scale (PES), and Proactive Work Behavior Scale (PWBS). With multiple regression we predict effect of personality traits and psychological empowerment on proactive behavior. The results were there were significant effects of personality traits and psychological empowerment on proactive behavior of start-up company employees.
\end{abstract}

Key words: personality traits, psychological empowerment, proactive behavior, start-up company.

\begin{abstract}
Abstrak
Penelitian ini bertujuan untuk mengetahui pengaruh tipe kepribadian dan pemberdayaan psikologis terhadap perilaku proaktif pada karyawan perusahaan start-up di Kota Bandung. Metode penelitian yang digunakan adalah metode kuantitatif dengan partisipan berjumlah 350 orang. Instrumen pada penelitian ini adalah Big Five Inventory (BFI) untuk mengukur tipe kepribadian, Psychological Empowerment Scale (PES) untuk mengukur pemberdayaan psikologis, dan Proactive Work Behavior Scale (PWBS) untuk mengukur perilaku proaktif. Teknik analisis data yang digunakan dalam penelitian ini adalah regresi sederhana dan regresi berganda. Hasil yang diperoleh menunjukkan bahwa terdapat pengaruh yang signifikan antara tipe kepribadian dan pemberdayaan psikologis terhadap perilaku proaktif pada karyawan perusahaan start-up di Kota Bandung.
\end{abstract}

Kata kunci: tipe kepribadian, pemberdayaan psikologis, perilaku proaktif, perusahaan startup

\section{PENDAHULUAN}

Start-up didefinisikan sebagai perusahaan yang baru didirikan dan berada dalam fase pengembangan serta penelitian untuk menemukan pasar yang tepat (Ryandono, 2018). Mayoritas start-up cenderung memanfaatkan teknologi informasi dan internet dalam beroperasi (Perdani, Widyawan, \& Santoso, 2018). Secara umum, perusahaan yang 
tergolong start-up memiliki beberapa karakteristik, seperti usia perusahaan 0-5 tahun, struktur organisasinya dinamis, serta biasanya bergerak di bidang teknologi dan beroperasi secara digital (Sitepu, 2017; Suwarno \& Silvianata, 2017). Ketatnya persaingan industri yang semakin kompetitif menjadi sebuah tantangan bagi perusahaan start-up untuk dapat bersaing dan bertahan (Anjani \& Gatari, 2019).

Selain itu, perubahan yang cepat dan dinamika kerja yang tinggi menuntut perusahaan start-up untuk menjadi lebih terdesentralisasi (tidak terpusat). Hal tersebut ditujukan guna menghasilkan inovasi secara cepat, mencapai fleksibilitas, dan melakukan perubahanperubahan yang berkelanjutan (Pradipta, 2015). Oleh sebab itu, perusahaan start-up perlu mendorong karyawannya untuk berperilaku proaktif serta menstimulus mereka agar berkontribusi lebih dalam bekerja sehingga perusahaan start-up mendapatkan keuntungan kompetitif yang berkelanjutan (Jaya, Ferdiana, Fauziati., 2017; Nurofi, 2014; Perdani, Widyawan, \& Santoso, 2018). Penting bagi karyawan untuk aktif dalam memulai sesuatu pekerjaan dibandingkan menunggu instruksi dalam melaksanakan sesuatu. Kemampuan inisiatif dalam bekerja seperti merencanakan lebih awal dan mempersiapkan diri terhadap potensi minat dan ancaman yang mungkin terjadi di masa sekarang maupun di masa mendatang menjadi peran penting bagi karyawan start-up dalam menghadapi ketatnya persaingan industri start-up (Belschak \& Hartog, 2010).

\section{Perilaku Proaktif}

Perilaku proaktif merupakan perilaku dimana seseorang secara sukarela mampu memberikan perubahan bagi lingkungan organisasi (Spychala \& Sonnentag, 2011). Perilaku kerja tersebut umumnya didorong oleh diri sendiri dan reaksi terhadap situasi kerja (Bindl \& Parker, 2011; Damayanti \& Ratnaningsih, 2018; Spychala \& Sonnentag, 2011). Bentuk perilaku proaktif dalam dunia kerja mencakup lingkup yang luas, meliputi pencegahan agar tidak terjadi masalah, aktif menyesuaikan diri dengan kondisi kerja yang baru, berani mengambil keputusan dan tanggung jawab, memberikan saran untuk perbaikan sistem atau prosedur kerja, meminta feedback dari rekan kerja atau atasan, menyampaikan ide atau pendapat terhadap pihak manajemen dan juga terkait aktivitas mencari kesempatan untuk belajar serta terlibat dalam proses pembelajaran (Ashford \& Black, 1996; Crant, 2000; Deviyanti \& Sasono, 2015; Grant \& Ashford, 2008; Morrison \& Phelps, 1999; Parker \& Collins, 2010; Parker, Williams, \& Turner, 2006; Van Dyne \& LePine, 1998).

Hakikatnya perilaku proaktif menjadi hal yang penting dalam industri start-up agar semua tujuan perusahaan bisa tercapai dan mampu bertahan dalam persaingan industri yang kompetitif. Karyawan yang proaktif umumnya dapat menyelesaikan tugas dan tanggung jawab pekerjaannya secara maksimal, memiliki tujuan akhir yang dicapai, dan dapat beradaptasi dengan situasi maupun lingkungan baru secara baik (Crant, 2000; Wijayanti, 2017). Perilaku proaktif dapat juga memberikan manfaat positif bagi 
karyawan, yaitu adanya penilaian positif dari atasan (Grant, Parker \& Collins, 2009), meningkatkan kesejahteraan subjektif (Clarke, dkk., 2016), kepuasan kerja dan kinerja (Belschack \& Hartog, 2010), efektivitas organisasi (Strauss \& Parker, 2014) dan komitmen terhadap organisasi (Belschack \& Den Hartog, 2010). Selain itu, perilaku proaktif menjadi pendorong kreativitas, inovasi, kemampuan adaptasi, fleksibilitas individual bagi keberhasilan organisasi (Damayanti \& Ratnaningsih, 2018).

Ketidakmampuan karyawan untuk proaktif saat bekerja akan membuat karyawan sulit beradaptasi dengan lingkungan sekitarnya, gagal mengidentifikasi kesempatan bahkan melepas kesempatan, menurun kepuasan kerjanya, ingin keluar dari perusahaan serta penurunan produktivitas perusahaan (Wijayanti, 2017; Windiarsih \& Etikariena, 2017). Parker, Bindl, \& Strauss (2010) menyatakan bahwa perilaku proaktif cenderung didorong oleh diri sendiri atau faktor individu (self-directed) sebagai respon terhadap situasi kerja yang bertujuan membawa perubahan bagi organisasi. Faktor individu itu dapat terdiri dari kepribadian, emosi, inteligensi, nilai-nilai yang dianut, sikap, dan pengalaman (Suhariadi \& Anshori, 2016). Sejumlah penelitian menemukan bahwa kepribadian memiliki potensi untuk memprediksi peran karyawan dalam mengambil sikap proaktif di dunia kerja (Chan \& Schmitt, 2000; Miller \& Jablin, 1991; Smithikrai \& Suwannadet, 2018; Thomas, Whitman \& Viswesvaran, 2010; Tidwell \& Sias, 2005; Wanberg \& Kammeyer-Mueller, 2000).

\section{Tipe Kepribadian}

Kepribadian merupakan suatu organisasi dinamis yang ada di dalam diri individu sebagai sistem psikofisik yang menentukan bagaimana seorang individu menyesuaikan diri secara khas dengan lingkungannya (Allport, 1937). Salah satu teori tentang kepribadian adalah big five personality yang dikembangkan oleh McCrae dan Costa (1999). Big Five adalah konsep kepribadian yang mengklasifikasikan kepribadian manusia dalam lima kepribadian yaitu, openness, conscientiousness, extraversion, agreeableness, dan neuroticism. Model ini telah digunakan oleh banyak peneliti sebagai kerangka acuan untuk mengeksplorasi serta menggambarkan keterkaitan antara karakteristik kepribadian dengan kinerja individu dan keterlibatan individu dalam bersikap proaktif (McCrae \& Costa, 1999; Smithikrai \& Suwannadet, 2018; Thomas, Whitman \& Viswesvaran, 2010). Penelitian terdahulu menunjukkan bahwa kepribadian openness, concientiousness, extraversion, agreeableness, dan neuroticism memiliki korelasi dengan perilaku proaktif (Smithikrai \& Suwannadet, 2018; Thomas, Whitman \& Viswesvaran, 2010; Tidwell \& Sias, 2005).

Kepribadian extraversion, conscientiousness, dan openness, ditemukan paling kuat berkaitan dengan perilaku proaktif dalam kerja (Ashford \& Black, 1996; Crant, 2000;

Parker \& Collins, 2010; Rode, dkk., 2008; Thomas, Whitman \& Viswesvaran, 2010; Van Dyne \& LePine, 1998; Wanberg \& Kammeyer-Mueller, 2000; Wang, dkk., 2018). 
Karyawan berkepribadian openness diasumsikan akan menerima berbagai kondisi serta pengalaman baru dalam bekerja (Digman, 1990; Rode, dkk., 2008; Thomas, Whitman \& Viswesvaran, 2010), karyawan dengan tipe kepribadian conscientiousness akan cenderung aktif mengantisipasi dan merencanakan metode untuk mengoptimalkan suatu hal yang kurang efisien dalam pekerjaan (Grant \& Ashford, 2008; Major, Turner, \& Fletcher, 2006), dan karyawan extraversion cenderung aktif membangun relasi positif di tempat kerja, (Major, Turner, \& Fletcher, 2006; Thomas, Whitman \& Viswesvaran, 2010). Sebaliknya, kayawan yang neurotis cenderung kurang aktif (Thomas, Whitman \& Viswesvaran, 2010; Tidwell \& Sias, 2005). Jadi, tidak semua tipe kepribadian secara positif berpengaruh terhadap perilaku proaktif (Parker \& Collins, 2010; Smithikrai \& Suwannadet, 2018).

Selain itu, perilaku proaktif dapat dipengaruhi juga pemberdayaan psikologis karyawan (Chen, dkk., 2018; Hashemi, dkk., 2012; Huang, 2017; Zhang, dkk., 2018). Dalam organisasi, pemberdayaan psikologis merupakan upaya untuk meningkatkan efektivitas organisasi dan menghadapi tantangan bisnis saat ini, terutama dalam konteks perubahan yang cepat dan dinamis (Conger \& Kanugo, 1988; Goksoy, 2017; Ramdhan, 2015; Spreitzer, 1995). Pemberdayaan psikologis juga merupakan salah satu bentuk karyawan dalam memotivasi diri sendiri (Yani, Supartha, \& Subudi, 2016).

Pemberdayaan psikologis didefinisikan sebagai peningkatan motivasi intrinsik individu terhadap tugas atau pekerjaannya (Spreitzer, 1995) yang terdiri dari dimensi: meaning, competence, self-determination, dan impact (Naderi \& Hoveida, 2013; Spreitzer, 1995). Empat dimensi ini menggambarkan perilaku proaktif yang berorientasi pada pekerjaannya. Karyawan yang berdaya psikologisnya tidak melihat situasi kerja sebagai pemberian, melainkan sesuatu yang dapat diciptakan oleh diri sendiri (Koesindratmono \& Septarini, 2011).

Melalui pemberdayaan psikologis, karyawan cenderung mampu meningkatkan kontrol pribadi dan memotivasi diri untuk terlibat dalam pekerjaan sehingga menghasilkan manajerial dan organisasi yang positif (Ariani, Wijono, \& Setiawan, 2016; Goksoy, 2017). Mereka akan lebih melihat kemampuan mereka dan akan mampu memengaruhi pekerjaan serta organisasi dengan cara yang lebih berarti. Mereka juga berusaha untuk melakukan pekerjaan lebih optimal, bertindak lebih mandiri, dan memiliki komitmen yang lebih tinggi sehingga mendorong mereka untuk berperilaku proaktif dalam bekerja (Ramdhan, 2015). Pemberdayaan psikologis dalam suatu organisasi menjadi solusi terhadap tingginya regulasi kerja yang menuntut karyawan memberikan kreativitasnya dan mampu bekerja sama agar organisasi efektif (Nursyamsi, 2013; Spreitzer, 1995).

Huang (2017) menemukan pengaruh pemberdayaan psikologis terhadap perilaku proaktif. Karyawan yang terberdayakan psikologisnya merasa lebih percaya diri dan berani mengambil keputusan serta bertanggung jawab dengan mandiri, meminta feedback dari rekan kerja atau pimpinan atas hasil kerjanya, dan secara aktif mencari kesempatan 
untuk terlibat dalam proses pembelajaran di tempat kerja. Penjelasan di atas menerangkan bahwa tipe kepribadian dan pemberdayaan psikologis memiliki suatu hubungan yang positif terhadap perilaku proaktif (Chen, dkk., 2018; Huang, 2017; Smithikrai \& Suwannadet, 2018; Thomas, Whitman \& Viswesvaran, 2010; Zhang, dkk., 2018). Namun, seberapa besar pengaruhnya pada karyawan start-up masih perlu dikaji lebih khusus. Karena peneliti belum menemukan studi tentang efek tipe kepribadian, pemberdayaan psikologis secara bersama-sama terhadap perilaku proaktif dalam konteks apapun maka peneliti memutuskan untuk menelitinya.

\section{METODE}

Teknik sampling yang digunakan dalam penelitian ini adalah non-probability sampling. Teknik non-probability ini tidak memberikan kesempatan yang sama bagi anggota populasi untuk dijadikan sampel (Creswell, 2010). Penarikan sampel dilakukan dengan teknik quota sampling, yaitu cara menentukan jumlah tertentu dari sampel yang diinginkan oleh peneliti sesuai dengan subjek penelitian (Stopher, 2012). Peneliti menentukan kuota partisipan sebanyak 350 orang. Penentuan partisipan penelitian sebanyak 350 ditentukan oleh tabel penarikan sampel dengan tingkat kesalahan 5\% (Sugiyono, 2015). Oleh karena itu, apabila pengambilan data telah memenuhi kuota sebanyak 350 orang maka pengumpulan data telah dianggap selesai (Stopher, 2012).

Instrumen untuk mengukur kepribadian dalam penelitian ini adalah Big Five Inventory (BFI) dari McCrae \& Costa yang diadaptasi oleh John, Naumann \& Soto (2008). Instrumen untuk pemberdayaan psikologis adalah Psychological Empowerment Scale (PES) (Spreitzer, 1995). Instrumen untuk perilaku proaktif adalah Proactive Work Behavior Scale (PWBS) (Spychala \& Sonnentag, 2011). Analisis data penelitian ini adalah regresi ganda untuk menguji pengaruh dua variabel independen terhadap dependen dan uji t dan analisis varian analisis demografis.

\section{HASIL}

\section{Analisis Demografis}

Pemberdayaan psikologis dan perilaku proaktif dapat dipengaruhi oleh demografi. Pemberdayaan psikologis dipengaruhi oleh status karyawan (kontrak/tetap), pekerjaan di luar job description, dan kedekatan dengan atasan. Sementara perilaku proaktif dipengaruhi oleh pendidikan, jabatan, status pekerjaan, bekerja sendiri atau bersama orang lain, pekerjaan di luar deskripsi kerja, dan kedekatan dengan atasan. Karyawan tetap, karyawan yang sering melakukan pekerjaan di luar deskripsi kerja, dan yang 
memiliki kedekatan dengan atasan memiliki pemberdayaan psikologis yang baik. Sementara itu, pendidikan yang lebih tinggi, karyawan tetap, bekerja sendiri, sering bekerja di luar deskripsi kerja, dan dekat dengan atasan cenderung lebih proaktif dalam bekerja daripada karyawan lain.

Tabel 1

Analisis Demografis Pemberdayaan Psikologis dan Perilaku Proaktif

\begin{tabular}{|c|c|c|c|}
\hline \multirow[t]{2}{*}{ No. } & \multirow[t]{2}{*}{ Demografi } & $\begin{array}{l}\text { Pemberdayaan } \\
\text { Psikologis }\end{array}$ & Proaktif \\
\hline & & Sig. & Sig. \\
\hline 1 & Usia & 0,305 & 0,655 \\
\hline 2 & Jenis Kelamin & 0,210 & 0,409 \\
\hline 3 & Pendidikan & 0,138 & $0,025^{*}$ \\
\hline 4 & Jabatan & 0,285 & $0,022 *$ \\
\hline 5 & Status Pekerjaan & $0,012 *$ & $0,036^{*}$ \\
\hline 6 & Masa Kerja & 0,308 & 0,307 \\
\hline 7 & Kedekatan dengan Rekan kerja & 0,511 & 0,878 \\
\hline 8 & Alasan Bertahan di Tempat Kerja & 0,506 & 0,195 \\
\hline 9 & Bekerja Sendiri atau Bersama Orang Lain & 0,129 & $0,006^{*}$ \\
\hline 10 & Pekerjaan di Luar Job Description & $0,002 *$ & $0,020 *$ \\
\hline 11 & Waktu Bekerja & 0,265 & 0,383 \\
\hline 12 & Kedekatan dengan Atasan & $0,001 *$ & $0,000 *$ \\
\hline 13 & Harapan & 0,421 & 0,219 \\
\hline 14 & Training & 0,874 & 0,445 \\
\hline
\end{tabular}

Tabel 2

Regresi Sederhana Tipe Keperibadian dan Pemberdayaan Psikologis terhadap Perilaku Proaktif

\begin{tabular}{cccc}
\hline Variabel & Koefisien Regresi & $\mathbf{t}$ & Sig \\
\hline Openness & 0,496 & 9,163 & 0,000 \\
\hline Conscientiousness & 0,453 & 8,616 & 0,000 \\
\hline Extraversion & 0,515 & 9,404 & 0,000 \\
\hline Agreeableness & 0,388 & 5,345 & 0,000 \\
\hline Neuroticsm & $-0,327$ & $-6,266$ & 0,000 \\
\hline Pemberdayaan Psikologis & 0,279 & 13,185 & 0,000
\end{tabular}

Tipe keperibadian openness, conscientiousness, extraversion, agreeableness, dan neuroticsm memiliki pengaruh yang signifikan $(\mathrm{p}<0,05)$ terhadap perilaku proaktif pada karyawan start-up. Extraversion memiliki nilai regresi yang paling besar terhadap perilaku proaktif sehingga memiliki efek yang paling besar terhadap perilaku proaktif dan neuroticism memiliki regresi yang paling dan satu-satunya yang berdampak negatif terhadap perilaku proaktif.

Secara bersama, semua tipe kepribadian dan pemberdayaan psikologis berpengaruh terhadap perilaku proaktif karyawan start-up. Secara regresi dua variabel memiliki 
pengaruh yang independen terhadap perilaku proaktif karena tidak ada perubahan yang berarti pada regresi setiap variabel dalam regresi ganda dengan regresi sederhana.

Tabel 3

Koefisien Regresi Tipe Keperibadian dan Pemberdayaan Psikologis terhadap Perilaku Proaktif

\begin{tabular}{ccccc}
\hline Model & Variabel & Koefisien regresi & t & Sig \\
\hline \multirow{2}{*}{1} & Openness & 0,345 & 7,212 & 0,000 \\
\cline { 2 - 5 } & Pemberdayaan psikologis & 0,239 & 11,621 & 0,000 \\
\hline \multirow{2}{*}{2} & Conscientiousness & 0,291 & 6,177 & 0,000 \\
\cline { 2 - 5 } & Pemberdayaan psikologis & 0,240 & 11,359 & 0,000 \\
\hline \multirow{2}{*}{3} & Extraversion & 0,336 & 6,734 & 0,000 \\
\cline { 2 - 5 } & Pemberdayaan psikologis & 0,233 & 11,051 & 0,000 \\
\hline \multirow{2}{*}{4} & Agreeableness & 0,155 & 2,406 & 0,017 \\
\cline { 2 - 5 } & Pemberdayaan psikologis & 0,263 & 11,911 & 0,000 \\
\hline \multirow{2}{*}{5} & Neuroticsm & $-0,212$ & $-4,741$ & 0,000 \\
\cline { 2 - 5 } & Pemberdayaan psikologis & 0,258 & 12,283 & 0,000 \\
\hline
\end{tabular}

\section{PEMBAHASAN}

\section{Analisis Demografis}

Pemberdayaan psikologis dan perilaku proaktif dapat dipengaruhi oleh demografi. Pemberdayaan psikologis dipengaruhi oleh status karyawan (kontrak/tetap), pekerjaan di luar job description, dan kedekatan dengan atasan. Sementara perilaku proaktif dipengaruhi oleh pendidikan, jabatan, status pekerjaan, bekerja sendiri atau bersama orang lain, pekerjaan di luar job description, dan kedekatan dengan atasan. Hasil penelitian di atas banyak memiliki kesesuaian dengan penelitian lain.

Karyawan tetap memiliki pemberdayaan psikologis lebih baik daripada karyawan kontrak (Devi, Noer, \& Rahmawati, 2017). Selain itu karyawan yang sering melakukan pekerjaan di luar deskripsi kerja memiliki pemberdayaan psikologis yang lebih baik daripada yang jarang (Ramadianty \& Aini, 2018). Demikian juga karyawan yang dekat dengan atasan memiliki pemberdayaan psikologis yang lebih baik daripada yang kurang dekat (Oktavianda \& Iqbal, 2018) karena lebih diapresiasi oleh atasan sehingga mampu mendorong dan membangkitkan semangat karyawan untuk bekerja (Koesindratmono \& Septarini, 2011).

Dalam hal perilaku proaktif, karyawan yang memiliki pendidikan lebih tinggi lebih proaktif (Pakpahan, Sukanto, dan Siswidiyanto, 2014) karena memiliki pengetahuan tertentu sehingga mampu serta cakap melaksanakan tugasnya dengan baik (Mahnaz, dkk., 
2013; Setiawan, Suwandy, \& Widjaja., 2017). Selain itu pekerja di kantor cenderung lebih proaktif dalam bekerja daripada pekerja lapangan (Sanny, Cahyani, \& Andhika, 2013) karena lingkungannya dapat memengaruhi semangat dan emosi dan lebih focus karena lebih kondusif (Robbins \& Coulter, 2005).

Mahnaz dkk (2013) bahwa karyawan tetap lebih proaktif dalam menyelesaikan pekerjaannya daripada karyawan kontrak atau periodic contract karena karyawan tetap secara umum lebih diberikan apresiasi dan tunjangan lebih oleh manajemen perusahaan dibandingkan karyawan kontrak sehingga secara tidak langsung dapat mempengaruhi perilaku proaktif karyawan tetap dan ini sesuai dengan penelitian ini. Sementara karyawan yang sering bekerja sendiri atau tidak cenderung tidak mengandalkan orang lain lebih aktif dalam bekerja (Spychala \& Sonnentag, 2013) karena berani menghadapi tantangan ataupun permasalahan karyawan sendiri dan berani mengambil keputusan dan tanggung jawab dibandingkan karyawan yang sering bekerja bersama orang lain.

Perilaku proaktif juga ditemukan berbeda berdasarkan seringnya kerja di luar deskripsi kerja lebih mampu berperilaku proaktif karena mereka secara sukarela bekerja dan memberikan kontribusi lebih dari apa yang dituntut secara formal dan secara keseluruhan meningkatkan efektivitas organisasi (Wikantari, 2014). Selain itu, penelitian lain menemukan bahwa kedekatan dengan atasan memberikan dampak positif terhadap meningkatnya perilaku proaktif karyawan dalam bekerja. Hal ini disebabkan hubungan yang positif dan sifatnya intim dengan atasan akan membangun rasa percaya diri seseorang dan memiliki kontrol untuk mengatur serta menyelesaikan pekerjaannya secara mandiri (Adnyaswari \& Adnyani (2017).

\section{Tipe kepribadian terhadap perilaku proaktif}

Keperibadian openness, conscientiousness, extraversion, agreeableness, neuroticsm memiliki pengaruh terhadap perilaku proaktif pada karyawan start-up. Kondisi tersebut sejalan dengan penelitian Anjani \& Gatari (2019) yang menemukan bahwa tipe kepribadian openness mempengaruhi perilaku proaktif karyawan. Mereka menemukan bahwa secara umum perusahaan start-up akan mencari karyawan yang memiliki kepribadian sesuai dengan kebutuhan. Beberapa karakteristik karyawan yang penting yang dicari oleh perusahaan start-up antara lain kreatif, inovatif serta memiliki fleksibilitas yang tinggi dalam mencari solusi dari permasalahan (Deen, 2017). Karakteristik tersebut sesuai dengan dinamika kerja perusahaan start-up yang dinamis dan penuh ketidakpastian (Bussgang, 2017).

Tipe kepribadian conscientiousness secara signifikan mampu mempengaruhi perilaku proaktif karyawan. Smithikrai \& Suwannadet (2018) menjelaskan bahwa saat karyawan secara sukarela menunjukkan inisiatif dan berani mengambil tindakan untuk memberikan perubahan bagi lingkungan organisasinya, mereka terlibat dalam proses untuk mencapai tujuan secara sadar, termasuk pencapaian dan pengembangan tujuan. Hal 
tersebut sejalan dengan penelitian McCrae \& Costa (1999), bahwa individu dengan trait conscientiousness memiliki kecenderungan bekerja yang disiplin untuk mencapai tujuannya secara sadar. Hasil penelitian tersebut memprediksi bahwa pada tahap awal suatu pekerjaan, karyawan start-up dengan conscientiousness yang tinggi akan lebih termotivasi untuk menunjukkan kinerjanya, terutama dalam berperilaku proaktif (Anjani \& Gatari, 2019).

Adanya pengaruh kepribadian extraversion terhadap perilaku proaktif karyawan start-up tidak terlepas dari karakteristik kepribadian ekstravert yang cenderung aktif, terbuka, berani bertindak sehingga mereka sukarela berpartisipasi dalam menyelesaikan pekerjaaan-pekerjaan yang ada (Wang, dkk., 2018). Perusahaan start-up yang menuntut karyawan untuk berhubungan sosial (Surur \& Handoyo, 2016) sangat cocok dengan individu yang extravert yang cenderung aktif dalam bersosialisasi (McCrae \& Costa, 1999). Menurut Parker \& Collins (2010) karyawan yang proaktif akan selalu mencari akar permasalahan untuk dipecahkan agar ada perubahan yang lebih baik.

Tipe kepribadian agreeableness menggambarkan jenis interaksi seorang individu (McCrae \& Costa, 1999). Individu yang agreeable cenderung memiliki sifat altruistik, baik hati dan penuh kepercayaan. Sifatnya yang ingin membantu orang lain membuat individu menjadi lebih responsif dan berempati (Pervin, Cervone \& John, 2005; Zulkarnain, Pohan, Sulistyawati., 2015). Individu yang agreable ini sangat mungkin lebih proaktif karena karyawan yang proaktif cenderung responsif dalam menyikapi sebuah keadaan ataupun permasalahan (Spychala \& Sonnentag, 2011). Karyawan start-up yang responsif dan peduli terhadap lingkungan sekitarnya akan bisa mengurangi permasalahan yang muncul yang disebabkan oleh tuntutan untuk mengerjakan tugas di luar deskripsi kerja karena kurangnya jumlah karyawan pada divisi tertentu (Damayanti \& Ratnaningsih, 2018; Deviyanti \& Sasono, 2015). Temuan sebelumnya menunjukkan hasil berbeda karena tipe kepribadian agreeableness memiliki korelasi negatif dengan perilaku proaktif. Ternyata karyawan yang agreable justru cenderung pasif menerima nilai dan norma-norma perusahaan dan mempertahankan kondisi yang ada (Rode dkk., 2008; Thomas, Whitman, \& Viswesvaran, 2010).

Tipe kepribadian neuroticsm berdampak negatif terhadap perilaku proaktif. Ini sesuai dengan penelitian sebelumnya oleh Thomas, Whitman, \& Viswesvaran (2010) yang menemukan bahwa tipe kepribadian neuroticsm secara signifikan mempengaruhi perilaku proaktif pada karyawan dengan arah korelasi negatif. Neuroticism menggambarkan penyesuaian emosi dan stabilitas pribadi seorang individu. Karyawan start-up dengan kepribadian neuroticism tinggi cenderung sulit berpikir realistis dan melakukan penyelesaian masalah secara efektif saat dihadapkan oleh tekanan (McCrae \& Costa, 1999; Zulkarnain, Pohan, Sulistyawati., 2015). Hal tersebut dapat berdampak negatif bagi karyawan sebab ritme kerja serta budaya perusahaan start-up yang sering mengalami perubahan (Jaya, Ferdiana, Fauziati., 2017; Perdani, Widyawan, \& Santoso, 2018). 
Penelitian lain juga menemukan kepribadian neuroticsm berkorelasi negatif dengan perilaku proaktif (Anjani \& Gatari, 2019; Thomas, Whitman \& Viswesvaran, 2010; Tidwell \& Sias, 2005). Individu dengan stabilitas emosi yang rendah cenderung mengalami tingkat kegelisahan dan depresi yang tinggi sehingga menghambat mereka untuk fokus dan memberikan perubahan di lingkungan pekerjaannya (Crant, 2000; Major, Turner, \& Fletcher, 2006; Thomas, Whitman, \& Viswesvaran, 2010).

\section{Pemberdayaan psikologis terhadap perilaku proaktif}

Pemberdayaan psikologis memiliki peran penting dalam meningkatkan perilaku proaktif karyawan dalam bentuk meminta feedback dari rekan kerja atau atasan, terlibat dalam kegiatan yang penuh kreativitas dan inovatif (Huang, 2017; Pieterse dkk, 2009; Spreitzer, 1995; Zhang \& Bartol, 2010). Karyawan yang merasa diberdayakan secara psikologis akan merasa yakin bahwa dirinya memiliki kemampuan untuk mengatasi segala permasalahan yang muncul, melakukan pekerjaan lebih optimal, bertindak lebih mandiri, dan mendapatkan komitmen yang lebih tinggi sehingga mendorong mereka untuk berperilaku proaktif dalam bekerja (Huang, 2017; Ramdhan, 2015; Spreitzer, 1995).

Temuan lainnya menunjukkan bahwa dengan adanya pemberdayaan psikologis, karyawan cenderung mampu meningkatkan rasa kontrol pribadi dan memotivasi diri untuk melakukan pekerjaan dengan baik, memaknai pekerjaanya lebih baik lagi, dan memiliki kepercayaan diri untuk mempengaruhi organisasi melalui peran mereka (Ariani, Wijono, \& Setiawan, 2016; Goksoy, 2017; Thomas \& Velthouse, 1990). Mereka tidak melihat situasi kerja sebagai pemberian, melainkan sesuatu yang dapat diciptakan oleh diri sendiri (Koesindratmono \& Septarini, 2011).

\section{Pengaruh tipe keperibadian dan pemberdayaan psikologis terhadap perilaku proaktif}

Kepribadian merupakan faktor internal yang memegang peranan penting bagi karyawan start-up untuk membangun perilaku proaktif dalam bekerja (Chan \& Schmitt, 2000; Miller \& Jablin, 1991; Smithikrai \& Suwannadet, 2018; Thomas, Whitman \& Viswesvaran, 2010; Tidwell \& Sias, 2005; Wanberg \& Kammeyer-Mueller, 2000). Semakin positif kondisi kepribadian seorang individu, maka kecenderungan karyawan untuk berperilaku proaktif akan semakin baik (Thomas, Whitman \& Viswesvaran, 2010). Selain kepribadian, pemberdayaan psikologis juga memiliki dampak yang positif terhadap perilaku proaktif. Karyawan yang memiliki pemberdayaan psikologis yang baik cenderung mampu mengontrol, mengelola, dan memilih cara untuk menyelesaikan suatu pekerjaan (Spreitzer, 1995). Kemampuan mengontrol cara bekerja dan mengambil keputusan di dalam pekerjaan merupakan bentuk perilaku proaktif dalam bekerja (Putri \& Ratnaningsih, 2018; Spychala \& Sonnentag, 2011).

Kepribadian dan pemberdayaan psikologis secara bersama-sama berpengaruh pada perilaku proaktif. Pada umumnya, karyawan dengan kepribadian opennes, agreableness, 
conscientiousnes, extaversion dan tidak neurotis serta memiliki pemberdayaan psikologis yang berkembang dengan baik akan lebih proaktif daripada jika tanpa pemberdayaan psikologis yang baik.

\section{DAFTAR PUSTAKA}

Adnyaswari, N.A., \& Adnyani, I.G.A.D. (2017). Pengaruh Dukungan Sosial Dan Burnout Terhadap Kinerja Perawat Rawat Inap Rsup Sanglah. E-Jurnal Manajemen Unud. 6(5), 2474-2500.

Adriansyah \& Suryani, A. I. (2018). Pengaruh Pemberdayaan Psikologis Terhadap Kinerja Karyawan Dengan Perilaku Kewargaan Organisasi Sebagai Variabel Mediasi Pada Karyawan Pt. Telkom Witel Aceh. Jurnal Ilmiah Mahasiswa Ekonomi Manajemen. 3(4), 1-15.

Allport, G. W. (1937). Personality: A psychological interpretation. New York: Holt.

Amalia, D.T.,\& Handoyo, S. (2018). Peran Psychological Empowerment dalam Hubungan antara Empowering Leadership dengan Perilaku Kerja Inovatif. Jurnal Psikologi Teori dan Terapan. 9, 77-90.

Anjani, S., \& Gatari, E. (2019). Hubungan Openness Dan Conscientiousness Terhadap Perilaku Kerja Inovatif: Peran Moderasi Dari Masa Kerja Pada Perusahaan Start-up. Jurnal Psikologi Talenta. 4(2), 182-195.

Ariani, D.S., Wijono, S., \& Setiawan, A. (2016). Hubungan Antara Pemberdayaan Psikologis Dan Komitmen Karier Pada Guru Sma Swasta Umum Binaan Disdikpora Kota Salatiga. Jurnal Psikodimensia, 15(1), 123-133.

Ashford, S. J., \& Black, J. S. (1996). Proactivity during organizational entry: The role of desire for control. Journal of Applied Psychology, 81(2), 199-214.

Belschak, F. D., \& Den Hartog, D. N. (2010). Pro-self, prosocial, and pro-organizational foci of proactive behaviour: Differential antecedents and consequences. Journal of Occupational and Organizational Psychology. 83, 475-498.

Bindl, U. K., \& Parker, S. K. (2011). Proactive work behavior: Forward-thinking and change-oriented action in organizations. In S. Zedeck (Ed.), APA Handbooks in Psychology. APA handbook of industrial and organizational psychology, Vol. 2. Selecting and developing members for the organization. Washington, DC, US: American Psychological Association.

Bindl, U. K., Parker, S. K., Totterdell, P., \& Hagger-Johnson, G. (2012). Fuel of the selfstarter:How mood relates to proactive goal regulation. Journal of Applied Psychology. 97(1), 134-150.

Bussgang, J. (2017). Are you suited for a start-up?. Hbr.org. Diakses 8 Agustus 2019, dari https://hbr.org/2017/11/are-you-suited-for-a-start-up. 
Chan, D \& Schmitt, N. (2000). Interindividual differences in intraindividual changes in proactivity during organizational entry: Alatent growth modeling approach to understanding newcomer adaptation. Journal of Applied Psychology, 85(2), 190-210.

Chen, Y., Liu, B., Zhang, L., \& Qian, S. (2018). Can leader "humility" spark employee "proactivity"? The mediating role of psychological empowerment. Leadership \& Organization Development Journal. 39(3), 326-339.

Clarke, S., Probst, T., Guldenmund, F., \& Passmore, J. (2016). The wiley blackwell handbook of the psychology of occupational safety and workplace health. WileyBlackwell: USA.

Conger, J.A. \& Kanungo, R.N. (1988). The Empowerment Process: Integrating Theory and Practice. Academy ol Management Feview. 1988, Vol. 13(3), 471-482.

Crant, J. (2000). Proactive behavior in organizations. Journal of Management, 26(3), $435-462$.

Creswell, J.W. (2010). Research Design: Pendekatan Kualitatif, Kuantitatif, dan Mixed. Edisi Ketiga. Alih Bahasa oleh Achmad Fawaid. Yogyakarta: Pustaka Pelajar.

Damayanti, A., \& Ratnaningsih, I. K. (2018). Hubungan Antara Psychosocial Safety Climate Dengan Proactive Work Behavior Pada Karyawan PT X Jakarta. Jurnal Empati. 7(1), 324-331.

Deen, A. (2017). What traits should you look for in your start-up's first employees?. Bplans.com. Diakses 8 Agustus 2019, dari https://articles.bplans.com/what-traitsshould-you-look-for-in-your-start-ups-first-employees/.

Devi, N. M. B. S., Noer, B. A., \& Rahmawati, Y. (2017). Analisis Perbandingan Pegawai Tetap dan Pegawai Outsourcing Ditinjau dari Pemberdayaan, Kepuasan Kerja, dan Komitmen Organisasional. Jurnal Sains dan Seni ITS Vol.6, No.2 ISSN:2337-3520.

Deviyanti, A. D., \& Sasono, A. D. (2015). Pengaruh Sumber Daya Pekerjaan (Job Resources) Dengan Keterikatan Kerja (Work Engagement) Sebagai Mediator Terhadap Perilaku Proaktif (Studi Pada Karyawan Pt Rga International Indonesia). EJurnal Ilmu Manajemen MAGISTRA. 1(1), 16-30.

Digman, J. M. (1990). Personality structure: Emergence of the five factor model. Annual Review of Psychology, 41, 417-440.

Dust, S.B., Resick, C.J., Margolis, J.A., Mawritz, M.B., Greenbaum, R.L. (2018). Ethical leadership and employee success: Examining the roles of psychological empowerment and emotional exhaustion. The Leadership Quarterly, 29(5), 570-583.

Frese, M., \& Fay, D. (2001). Personal initiative: An active performance concept for work in the 21st century. Research in Organizational Behavior, 23: 133-187.

Goksoy, A. (2017). The Role of Psychological Empowerment and Organizational Citizenship Behaviors on Employee Resistance to Change. European Journal of Interdisciplinary Studies. 7(2), 84-92.

Grant, A. M., \& Ashford, S. J. (2008). The dynamics of proactivity at work. Research in Organizational Behavior. 28, 3-34. 
Grant, A., Parker, S., \& Collins, C. (2009). Getting credit for proactive behavior: Supervisor reactions depend on what you value and how you feel. Personel Psychology. 62(1), 31-35.

Hashemi, S. M. K., Nadi, H. K., Hosseini, S. M., \& Revanfar, A. (2012). Agricultural Personnel's Proactive Behavior: Effects of Self efficacy Perceptions and Perceived Organizational Support. International Business and Management. 4(1), 83-91.

Huang, J. (2017). The Relationship Between Employee Psychological Empowerment And Proactive Behavior: Self-Efficacy As Mediator. Social Behavior And Personality, 45(7), 1157-1166.

Jaya, M. A., Ferdiana, R., Fauziati, S. (2017). Analisis Faktor Keberhasilan SDM Startup Yang Ada Di Yogyakarta. Prosiding SNATIF (hlm.175-179) Yogyakarta: Universitas Muria Kudus.

John, O. P., Naumann, L. P., \& Soto, C. J. (2008). Paradigm shift to the integrative Big Five trait taxonomy: History, measurement, and conceptual issues. In O. P. John, R. W. Robins, \& L. A. Pervin (Eds.), Handbook of personality: Theory and research (pp. 114-158). New York, NY: Guilford Press.

Koesindratmono, F., \& Septarini, B.G. (2011). Hubungan antara masa kerja dengan pemberdayaan psikologis pada karyawan PT. Perkebunan Nusantara X (Persero). Jurnal INSAN, 13(1), 50-57.

Mahnaz, M. A., Mehdi, M., Jafar, K. M., \& Abbolghasem, P. (2013). The Effect of Demographic Characteristics on Organizational Citizenship Behavior in the Selected Teaching Hospitals in Tehran. African Journal of Business Management, 7(34), 33243331.

Major, D. A., Turner, J. E., \& Fletcher, T. D. (2006). Linking proactive personality and the Big Five to motivation to learn and development activity. Journal of Applied Psychology, 91, 927-935.

McCrae, R. R., \& Costa, P. T. (1999). A five-factor theory of personality. In L. A. Pervin \& O. P. John (Eds.), Handbook of personality (pp. 139-153). New York: Guilford.

Meyerson, S. L. \& Kline, T. J. B. (2008). Psychological and Environmental Empowerment: Antecedents and Consequences. Leadership \& Organization Development Journal. 29(5). 444-460.

Miller, V. D., \& Jablin, F. M. (1991). Information-seeking during organizational entry: Influences, tactics, and a model of the process. Academy of Management Review, 16(1), 92-120.

Morrison, E. W., \& Phelps, C. C. (1999). Taking charge at work: Extrarole efforts to initiate workplace change. Academy of Management Journal, 42: 403-419.

Mount, M. K., Barrick, M. R., \& Stewart, G. L. (1998). Five-factor model of personality and performance in jobs involving interpersonal interactions. Human Performance, 11, $145-165$.

Muttaqin, F. (2017). Pengaruh Tipe Kepribadian Terhadap Perilaku Inovatif Pada Pelaku Industri Kreatif Di Kota Bandung. Skripsi. Fakultas Ilmu Pendidikan, Universitas Pendidikan Indonesia, Bandung. 
Naderi, N., \& Hoveida, R. (2013). The relationship between Organizational Citizenship Behavior (OCB) and Human Resources Empowerment (HRE) Case study: University of Isfahan (Iran). International Journal of Human Resource Studies, 3(2), 69-78.

Nurofi, A. (2014). Meningkatkan Perilaku Proaktif Karyawan Melalui Peran Pimpinan Dan Sistem Kontrol. Jurnal Ilmu Manajemen dan Akuntansi Terapan. 5(1), 84-91.

Nursyamsi, I. (2013). Organizational Citizenship Behavior Dan Pemberdayaan Terhadap Komitmen Organisasi Serta Dampaknya Terhadap Kinerja Karyawan. Jurnal Keuangan dan Perbankan, 17(3), 488-498.

Oktavianda, A.A., \& Iqbal, M. (2018). Pengaruh Leader Member Exchange (Lmx) Dan Motivasi Kerja Terhadap Loyalitas Karyawan (Studi Pada Karyawan Pt. Telekomunikasi Indonesia Tbk Witel Jatim Malang Selatan). Jurnal Administrasi Bisnis. 58(2), 179-187.

Pakpahan, E.S., Siswidiyanto., \& Sukanto. (2014). Pengaruh Pendidikan Dan Pelatihan Terhadap Kinerja Pegawai (Studi Pada Badan Kepegawaian Daerah Kota Malang). Jurnal Administrasi Publik. 2(1), 116-121.

Parker, S. K., Bindl, U. K., \& Strauss, K. (2010). Making Things Happen: A Model of Proactive Motivation. Journal of Management. 36(4), 827-859.

Parker, S. K., \& Collins, C. (2010). Taking Stock: Integrating and differentiating multiple proactive behaviors. Journal of Management. 36(3), 633-662.

Parker, S. K., Williams, H. M., \& Turner, N. (2006). Modeling the antecendents of proactive behavior at work. Journal of Applied Psychology. 91(3), 636-52.

Perdani, M. D. K., Widyawan., \& Santoso, P. I. (2018). Faktor-Faktor Yang Mempengaruhi Pertumbuhan Start-up Di Yogyakarta. Seminar Nasional Teknologi Informasi dan Komunikasi. Yogyakarta, 23-24 Maret 2018, 337-349.

Pervin, L. A., Cervone, D., \& Oliver, P. J.(2012). Psikologi kepribadian: Teori dan Penelitian (edisi ke-9). Jakarta: Kencana Prenada Media Group.

Pieterse, A. N., van Knippenberg, D., Schippers, M., \& Stam, D. (2010). Transformational and transactional leadership and innovative behavior: The moderating role of psychological empowerment. Journal of Organizational Behavior. 31(4), 609-623.

Prabarini, P., \& Suhariadi, F. (2018). Iklim Keselamatan Kerja dan Big Five Personality Sebagai Prediktor Perilaku Keselamatan Karyawan. Jurnal Psikologi Teori dan Terapan. 9(1), 1-16.

Pradipta, P. B. (2014). Pengaruh Self-Efficacy Terhadap Perilaku Proaktif Dengan Work Engagement Sebagai Variabel Mediasi. Skripsi. Fakutas Ekonomika dan Bisnis, Universitas Gadjah Mada, Yogyakarta.

Putri, A. P., \& Ratnaningsih, I. Z. (2018). Hubungan Antara Psychological Empowerment Dengan Perilaku Kewargaan Organisasi Pada Karyawan Perusahaan Distributor PT. X. Jurnal Empati. 7(1), 352-361

Rahmasari, L. (2011). Peningkatan Motivasi Melalui Pemberdayaan Psikologis Dan Dampaknya Terhadap Kinerja Karyawan. Jurnal Ilmiah Informatika. 2(1), 57-67. 
Ramadianty, D., \& Aini, E.K. (2018). Pengaruh Motivasi Terhadap Organizational Citizenship Behavior (Ocb) Karyawan Gen-X Dan Millenials (Studi Pada Karyawan Pt Temprina Media Grafika Surabaya). Jurnal Administrasi Bisnis. 60(2), 1-9.

Ramdhan, D. (2015). Kepemimpinan Transformasional dan Pemberdayaan Psikologis terhadap Komitmen Organisasi dan Implikasinya Kinerja Pegawai. Jurnal Kontingensi, 3(2), 117-128.

Ramdhani, A. (2012). Adaptasi Bahasa dan Budaya Inventori Big Five. Jurnal Psikologi. 39(2), $189-207$.

Robbins, S., and Coulter, M. (2005). Manajemen: Edisi ke 7. Jakarta: Gramedia

Rode, J. C., Arthaud-Day, M. L., Mooney, C. H., Near, J. P., \& Baldwin, T. T. (2008). Ability and personality predictors of salary, perceived job success, and perceived career success in the initial career stage. International Journal of Selection and Assessment, 16, 292-299.

Ryandono, M. N. H. (2018). FinTech Waqaf: Solusi Permodalan Perusahaan Start-up Wirausaha Muda. Jurnal Studi Pemuda. 7(2), 111-121.

Sanny, L., Cahyani, R.A.B., \& Andhika, Y. (2013). Analisis Pengaruh Lingkungan Kerja Dan Motivasi Terhadap Kreativitas Karyawan Perum Pegadaian (Kanwil). Binus Business Review. 4(1), 389-397.

Setiawan, A., Suwandy, K., \& Widjaja, D.C. (2017). Analisis Perbedaan Organizational Citizenship Behavior Karyawan Dilihat Dari Faktor Demografis Di Kafe Excelso Surabaya. Jurnal Hospitality dan Manajemen Jasa. 5(1), 1-15.

Smithikrai, C., \& Suwannadet, J. (2018). Authentic Leadership and Proactive Work Behavior: Moderated Mediation Effects of Conscientiousness and Organizational Commitment. The Journal of Behavioral Science. 13(2), 94-106.

Sitepu, S. N. B. (2017). Pengaruh Faktor Internal Terhadap Keberhasilan Start-Up Bisnis Di Kota Surabaya. Jurnal Manajemen Teori dan Terapan. 10(1), 37-50.

Spreitzer, G.M. (1995). Psychological empowerment in the workplace: dimension, measurement, and validation. Academy of Management Journal, 38(5), 1442-1465.

Spychala, A., \& Sonnentag, S. (2011). The dark and the bright sides of proactive work behavior and situational constraints: Longitudinal relationships with task conflicts. European Journal of Work and Organizational Psychology. 20(5), 654-680.

Stopher, P. (2012). Collecting, Managing, and Assessing Data Using Sample Surveys. Cambridge: Cambridge University Press.

Strauss, K., \& Parker, S. K. (2014). Effective and sustained proactivity in the workplace: A self-determination theory perspective. In M.Gagne (Ed.), The Oxford handbook of work engagement, motivation, and self-determination theory. New York, NY: Oxford University Press.

Sugiyono. (2015). Metode penelitian kuantitatif, kualitatif, dan R\&D. Bandung: Alfabeta.

Suhariadi, F., \& Anshori, M. (2016). Forming Values of Productive Behaviors. The International Journal of Organizational Innovation. 8(4), 64-76. 
Surur, A.R.S., \& Handoyo, S. (2016). Pengaruh Tipe Kepribadian Big Five Inventory terhadap Employee Creativity di Rubrik X PT J. Skripsi. Fakultas Psikologi, Universitas Airlangga, Surabaya.

Suwarno, D. J., \& Silvianita, A. (2017). Knowledge Sharing Dan Inovasi Pada Industri Start-up. Jurnal Ecodemica. 1(1), 98-106.

Thomas, K. W., \& Velthouse, B. A. (1990). Cognitive elements of empowerment: An "interpretive" model of intrinsic task motivation. Academy of Management Review, $15(4), 666-681$.

Thomas, J. P., Whitman, D. S., \& Viswesvaran, C. (2010). Employee proactivity in organizations: A comparative meta-analysis of emergent proactive constructs. Journal of Occupational and Organizational Psychology. 83(2), 275-300.

Tidwell, M., \& Sias, P. (2005). Personality And Information Seeking: Understanding How Traits Influence Information-Seeking Behaviors. Journal of Business Communication. 42(1), 51-77.

Tuuli, M.M., \& Rowlinson, S. (2009). Performance Consequences of Psychological Empowerment. Journal of Construction engineering and Management. 135(12), 13341347.

Uzonwanne, F.C. (2014). Organizational Citizenship Behaviour and Demographic Factors among Oil Workers in Nigeria. Journal of Humanities And Social Science, 10(8), 87-95.

Van Dyne, L., \& LePine, J. (1998). Helping and voice extra-role behaviors: Evidence of construct and predictive validity. Academy of Management Journal, 41(1), 108-119.

Wanberg, C. R., \& Kammeyer-Mueller, J. D. (2000). Predictors and outcomes of proactivity in the socialization process. Journal of Applied Psychology, 85(3), 373385 .

Wang, Y., Ang, C., Jiang, Z., \& Wu, C. H. (2018). The role of trait extraversion in shaping proactive behavior: A multilevel examination of the impact of high-activated positive affect. Personality and Individual Differences. 136(11), 107-112.

Widiasih, P.A. (2017). Peran Kepemimpinan Profetik dan Pemberdayaan Psikologis dalam Membangun Keterikatan Kerja Karyawan. Jurnal Ilmiah Penelitian Psikologi: Kajian Empiris \& Non-Empiris, 3(1), 31-41.

Wijayanti, E. Y. (2017). Hubungan Perilaku Proaktif Terhadap Intensi Turnover Pada Management Trainee PT “ $X$ ”. Jurnal Ilmiah Psikologi Inquiry. 8(2), 75-87.

Wikantari, M. (2014). Pengaruh Faktor-Faktor Personality Dan Procedural Justice Terhadap Organizational Citizenship Behavior. Jurnal Bijak, 11(2), 1-11.

Windiarsih, R \& Etikariena, A. (2017). Hubungan Antara Kepribadian Proaktif dan Perilaku Kerja Inovatif di BUMN X. Jurnal Psikogenesis. 5(2), 123 - 134.

Yani, I.M., Supartha, W.G., \& Subudi, M. (2016). Pengaruh Pemberdayaan Dan Kepuasan Kerja Terhadap Komitmen Organisasional Guru Di Smkn 1 Mas Ubud. EJurnal Ekonomi dan Bisnis Universitas Udayana, 5(12), 4177-4208. 
Zhang, X., \& Bartol, K. M. (2010). Linking empowering leadership and employee creativity: The influence of psychological empowerment, intrinsic motivation, and creative process engagement. Academy of Management Journal. 53(1), 107-128.

Zhang, J., Song, L. J., Wang, Y., \& Liu, G. (2018). How authentic leadership influences employee proactivity: the sequential mediating effects of psychological empowerment and core self-evaluations and the moderating role of employee political skill. Frontiers of Business Research in China. 12(5), 1-21.

Zulkarnain, Pohan, V. G. R., \& Sulistyawati, E. (2015). Kecemasan Dalam Menghadapi Assessment Centre di Kalangan Pekerja Telekomunikasi. Jurnal Psikologi. 42(3), 259277. 